\title{
DEGRADAÇÃO DE PESTICIDAS POR FUNGOS - UMA REVISÃO
}

\author{
J. A. J. BENEVIDES* e G. M. MARINHO \\ Instituto Federal de Educação, Ciência e Tecnologia do Ceará - IFCE \\ jorgeana.benevides@ifce.edu.br*
}

Artigo submetido em junho/2013 e aceito em outubro/2015

DOI: $10.15628 /$ holos.2015.1488

\section{RESUMO}

Os pesticidas são reconhecidos como substâncias ou mistura de substâncias que são utilizadas com o objetivo de prevenir, destruir ou controlar qualquer praga. $\mathrm{O}$ Brasil é considerado como um dos maiores consumidores de produtos químicos. O Ceará apareceu no Censo Agropecuário do IBGE como o quarto estado brasileiro em número de estabelecimentos que comercializam agrotóxicos. Muitas tecnologias têm sido desenvolvidas no intuito de degradar ou remover estes pesticidas do meio ambiente, pois são potencialmente poluidores. Dentre estas, estão os experimentos de natureza físico-química e biológica, e nesta última se destaca o uso tanto de fungos, como de bactérias agindo como biorremediadores. O emprego de fungos no tratamento de efluentes começou a ser estudado no final do século passado, tendo ocorrido nas duas últimas décadas um incremento nas pesquisas de biodegradação. Eles têm sido usados em várias pesquisas por serem considerados biodegradadores eficientes de moléculas como: fenol, benzeno, tolueno, xileno e pesticidas. Esta revisão tem como objetivo analisar a eficiência fúngica na decomposição de pesticidas.

PALAVRAS-CHAVE: Tratamento, Aspergillus niger, biorremediação.

\section{DEGRADATION OF PESTICIDES IN FUNGI - A REVIEW}

\begin{abstract}
Pesticides are recognized as a substance or mixture of substances that are used for the purpose of preventing, destroying or controlling any pest. Brazil is considered one of the largest consumers chemicals. Ceará appeared in the IBGE Agricultural Census as the fourth state in Brazil in number of establishments that sell pesticides. Many technologies have been developed in order to degrade or remove these pesticides from the environment, as they are potentially polluting. Among these are the experiments of physical-chemical and
\end{abstract}

biological, and the latter highlights the use of both fungi and bacteria acting as bioremediators. The use of fungi in wastewater treatment began to be studied at the end of the last century have occurred in the last two decades an increase in research biodegradation. They have been used in several studies to be considered effective biodegradadores molecules such as phenol, benzene, toluene, xylene and pesticides. This review aims to analyze the efficiency in fungal decomposition of pesticides.

KEYWORDS: Treatment, Aspergillus niger, bioremediation. 


\section{INTRODUÇÃO}

O aumento vertiginoso da população mundial e a busca cega pelo desenvolvimento têm conduzido o homem a buscar mais espaço e retirar cada vez mais volume de recursos da natureza. Nas últimas décadas, esse incremento populacional tem gerado uma demanda crescente por alimentos e causado impactos no meio ambiente difíceis de serem quantificados. Como uma das consequências observáveis, na produção agrícola, o uso de pesticidas passou a ser cada vez mais frequente no mundo, e o Brasil aparece em destaque neste cenário de abuso.

A FAO - Organização para a Alimentação e Agricultura das Nações Unidas - define os pesticidas como substâncias, ou mistura dessas, que são utilizadas com o objetivo de prevenir, destruir ou controlar qualquer praga, incluindo vetores de doenças animais ou vegetais.

No país há, aproximadamente, mais de mil produtos comerciais de agrotóxicos diferentes que, são elaborados a partir de 450 ingredientes ativos. O Ceará apareceu no Censo Agropecuário do Instituto Brasileiro de Geografia e Estatística em 2006, como o quarto estado brasileiro em número de estabelecimentos que comercializam agrotóxicos. Embora não se tenha dados precisos sobre o controle do fluxo de agrotóxicos, segundo a Lei brasileira 7.802/1989 (LEI ORDINÁRIA 11/07/1989 Art. 3ㅇ) os agrotóxicos, seus componentes e afins, de acordo com definição do o art. 2o desta Lei, só poderão ser produzidos, exportados, importados, comercializados e utilizados, se previamente registrados em órgão federal de acordo com as diretrizes e exigências dos órgãos federais responsáveis pelos setores da saúde, do meio ambiente e da agricultura.

Os componentes químicos dos agrotóxicos têm grande potencial de contaminação das águas superficiais, subterrâneas e sedimentos devido às suas propriedades físicas e químicas, tais como: solubilidade, adsorção, deslocamento, persistência e toxicidade. Sendo estes dois últimos, os fatores de maior poder contaminante. $O$ homem e os animais aparecem nesta rota perigosa devido ao efeito bioacumulativo na cadeia de transferência de efeito tóxicos pela ingestão de água e alimentos contaminados.

Os fungos são os agentes mais importantes de degradação na Terra. Além disso, são considerados biodegradadores eficientes de polímeros de plantas naturais.

Esta revisão tem como objetivo analisar a eficiência fúngica na decomposição de pesticidas com base em resultados de pesquisas recentes relacionadas a este tema para comparação de resultados.

\section{PESTICIDAS}

\subsection{Histórico}

Pesticidas, venenos, defensivos agrícolas, agrotóxicos são alguns dos vários termos utilizados, tanto pelo senso comum quanto pela comunidade científica, para referir-se a um grupo de compostos que são utilizados no combate a pragas. O termo pode também incluir substâncias utilizadas como reguladores de crescimento vegetal, desfolhantes, dissecadores, agentes para prevenir a queda prematura de frutas e substâncias aplicadas à plantação, antes 
e/ou depois da colheita, para prevenir a deterioração durante a estocagem e/ou transporte (WHO/ UNEP, 1990).

O uso de produtos químicos para o controle biológico data de um milênio antes de Cristo. As escrituras gregas, chinesas e romanas relatavam o uso de arsênio no combate a insetos e cloreto de sódio para controlar ervas daninhas (MARASCHIN, 2003). Mas foi apenas em 1874 que Othomar Zeidler sintetizou o DDT (dicloro-difenil-tricloroetano) e, posteriormente, em 1939, Paul Muller descobriu suas propriedades inseticidas (MORACCI, 2008). Tempos depois, o que se achou ser um grande aliado no controle de insetos vetores como o da malária, tornou-se uma preocupação ambiental e de saúde humana pelas propriedades carcinogênicas e teratogênicas que todos os organoclorados possuem.

Segundo Alves Filho (2002), em 1890 foi registrado o uso do cloreto de mercúrio como bactericida no tratamento de sementes. Tendo sido reconhecido o potencial químico no combate a pragas, nas cinco décadas seguintes vislumbrou-se um grande aumento no uso de produtos químicos para a proteção de plantas contra pragas e doenças. Dentre estes produtos que ficaram marcados como a primeira geração de agrotóxicos, se destacaram os constituídos basicamente por compostos inorgânicos à base de flúor (F), arsênio (As), mercúrio ( $\mathrm{Hg}$ ), selênio $(\mathrm{Se})$, chumbo $(\mathrm{Pb})$, sais de cobre $(\mathrm{Cu})$ e zinco $(\mathrm{Zn})$. Seu uso foi sendo banido com o tempo devido às características danosas destes para o homem e meio ambiente. $\mathrm{O}$ tiocianato $(\mathrm{R}-\mathrm{S}-\mathrm{C} \equiv \mathrm{N})$ fez parte da composição química do primeiro inseticida, sendo conhecido no mercado pelo nome de Lethane 384 (1932). Começava aí a segunda geração de agrotóxicos. Contudo, foi apenas vinte anos depois com o desenvolvimento da indústria química que ocorreu a difusão progressiva de biocidas sintetizados. Durante a Segunda Guerra Mundial, indústrias químicas alemã e americana sintetizaram diversos produtos, dentre eles alguns derivados do ácido fosfórico $\left(\mathrm{H}_{3} \mathrm{PO}_{4}\right)$. Posteriormente, produtos a base deste composto deram origem aos inseticidas do grupo Paration.

Ainda de acordo com o mesmo autor, com a publicação do livro da pesquisadora americana Rachel Carson, Silient Spring, em 1962 deu-se início, por pressão da opinião pública, às primeiras iniciativas de reavaliação do uso indiscriminado dos agrotóxicos e de sua real eficácia. A pesquisadora chamou a atenção para a urgente necessidade de mudança em busca de práticas alternativas de menor impacto ao ambiente e a saúde humana. Em decorrência deste movimento houve a criação da agência americana EPA (Environmental Protecion Agency) e em seguida, o banimento do uso agrícola de produtos organoclorados (National Research Council, 2000). A terceira geração de agrotóxicos apareceu ainda nesta mesma década com formulações à base de semioquímicos (ferormônios), os fisiológicos (diflubenzuron), os biológicos (Bacillus thuringiensis) e os piretroides.

Os agrotóxicos da quarta geração se caracterizavam por ter uma ação mais específica sobre a praga. Nesta tentativa, vários estudos foram desenvolvidos e apontavam novas possibilidades de uso de pesticidas. Estudos entomológicos, por exemplo, permitiram o desenvolvimento de produtos tais como o Methoprene (metopreno), que atuam sobre o sistema endócrino dos insetos inibindo o seu processo de maturação, já que este composto funciona de forma similar a um hormônio juvenil que regula o crescimento dos insetos (National Research Council, 2000; Organização Mundial da Saúde, 2008). 
As propriedades físico-químicas dos agrotóxicos, a quantidade e a frequência de uso, métodos de aplicação, características bióticas e abióticas do ambiente e as condições meteorológicas determinarão qual será o destino dos pesticidas no ambiente. Por isso não se pode prever um modelo para o comportamento destes pesticidas e sua interação com os ecossistemas. Entretanto, alguns processos conhecidos e descritos podem predizer como o produto se comportará interagindo com as partículas do solo e com outros componentes, com sua velocidade de evaporação, solubilidade em água e bioacumulação. Os recursos hídricos agem como integradores de todos os processos biogeoquímicos em qualquer região, assim, superficiais ou subterrâneos, são os principais destinos de pesticidas, principalmente quando aplicados na agricultura (KLINGMAN; ASHTON; NOORDHOFF, 1982).

A partir do ano de 1979 aumentou a preocupação com a contaminação de recursos hídricos com pesticidas quando os primeiros traços destes compostos foram detectados nos EUA. Mesmo em baixas concentrações foram observados resíduos de pesticidas em amostras de água subterrânea em países como Grã-Bretanha, Alemanha, Estados Unidos, Grécia, Bulgária, Espanha, Portugal e Brasil (RIBEIRO et al., 2007).

Na Resolução no 001/86 do Conselho Nacional de Meio Ambiente, define impacto ambiental como sendo "qualquer alteração das propriedades físicas, químicas ou biológicas do meio ambiente, causada por qualquer forma de matéria ou energia resultante da atividade humana" (Resolução no 001/86). Esta definição de impacto ambiental transformou-se em categoria básica das políticas públicas, "pilar central do ordenamento jurídico que define alguns dos principais instrumentos de nossa política ambiental" (TORRES, 2000).

\subsection{Legislação Ambiental e Tipificação}

No tocante à legislação ambiental para produção, uso e descarte de agrotóxicos, cada país apresenta autonomia para criar leis, decretos ou normas que norteiem o uso destes compostos. A US Environmental Protection Agency é um órgão americano que tem como um dos seus objetivos atuar no controle do uso de substâncias tóxicas. Esta agência está amparada pela Federal Insecticide, Fungicide and Rodenticide Act e sob as leis dos Estados com autoridade para registrar e regular o uso de pesticidas no país. A EPA se utiliza de várias ferramentas como parcerias, programas educacionais, como também fomenta a criação de leis e normas buscando tanto a garantia da segurança da saúde humana como do meio ambiente. Mesmo sendo de competência do Congresso americano a aprovação das leis, cabe a EPA e outras agências federais tanto a criação como também o cumprimento delas. A EPA também regulamenta o uso de agrotóxicos importados para os EUA e faz parte do conselho em diversos países atuando na construção de acordos de regulação e atividades de coordenação. A lei federal americana exige que antes da comercialização de qualquer pesticida no país, este deverá antes ter passado pelo crivo da EPA que assegurará, ou não, que a substância não causará dano algum à saúde humana ou ao meio ambiente. Para isso, o órgão conta com um banco de estudos e teste que validarão ou não o novo pesticida (US Environmental Protection Agency, 2013).

Num estudo comparativo feito pela Fundação canadense David Suzuki, entre os níveis de tolerância à presença de pesticidas em alimentos percebeu-se que a União Europeia (EU) tem padrões mais rígidos, ou seja, menor limite máximo de resíduos, para a maioria dos pesticidas. A 
Austrália segue em segundo e na outra extremidade aparecem o Canadá e os EUA com os mais fracos padrões de controle, consequentemente, menor proteção a saúde (SUZUKI, 2006).

A EU tem buscado adotar estratégias que aliem eficiência com baixo impacto negativo ao meio ambiente e à saúde humana. Para isso eles adotam medidas mais rigorosas no controle da comercialização destes produtos. As ONGs europeias têm chamado a atenção para as demasiadas brechas presentes na legislação, mas a indústria contra argumenta que estas exceções são indispensáveis. A crescente utilização de pesticidas proibidos tem-se apresentado como um risco não só para a população como para a natureza (ERBACH, 2012).

Embora os agrotóxicos tenham aparecido no cenário brasileiro nos anos 40 , foi na década seguinte, impulsionados pelas novas tecnologias, que eles começaram a ser comercializados de forma mais maciça pelo mercado agrícola e pecuário. Neste contexto, entra o uso de defensivos agrícolas na busca do controle de fitopatógenos visando um aumento na produtividade e diminuição de custos (CONWAY, 2003).

Com o aparecimento dos primeiros casos de contaminação tanto no meio ambiente (solos, alimentos e águas) quanto em trabalhadores rurais, a partir dos anos 70 deu-se início às pressões ambientalistas internacionais para a criação de formas menos agressivas e mais equilibradas de utilização destes químicos (LIMA, 2008). Os países mais desenvolvidos partiram na frente em busca de medidas de controle do impacto ambiental através da aprovação de projetos e fiscalização de todo o processo. No Brasil, foi somente nos anos 80 que surgiram as primeiras legislações sobre controle ambiental e as indústrias privadas foram pressionadas a adotar medidas de adequação no uso destes compostos.

Entre as pautas mais importantes das duas últimas décadas estão as questões que envolvem a institucionalização da gestão eficiente e exploração dos pesticidas. O Brasil aparece em primeiro lugar seguido pelos EUA no uso de defensivos agrícolas. Segundo dados da Associação Niteroiense de Deficientes Físicos (2009) as cifras giraram em torno de US\$ 7,1 bilhões para o mercado brasileiro ante US\$ 6,6 bilhões para os americanos. A justificativa de valores tão altos pode ser entendida levando-se em conta fatores como as características agrícolas que o país apresenta, pelos expressivos números na sua produção, exportação e tecnologias mais efetivas, bem como pela ampla cobertura legal que recebe.

No Brasil, a Lei Federal 7802/1989 (Brasil, 1989) é o referencial legal mais importante neste sentido. É ela que rege os registros de um produto agrotóxicos, seu descarte e uso de forma geral, amparada pelo Decreto 4074/02 (Brasil, 2002). É esta Lei que norteia a comercialização a partir da obtenção de um registro mediante avaliação de sua eficácia e dos impactos do agrotóxico no meio ambiente e na saúde coletiva. No artigo 2ㅇ, inciso I da referida Lei, encontramos a definição de agrotóxicos como todos os produtos e agentes de processos físicos, químicos ou biológicos utilizados na área de produção, armazenamento e beneficiamento agrícola, em floras nativas ou cultivadas, ou em outros ecossistemas, áreas urbanas ou industriais com o objetivo de preservação da fauna e flora no combate a pragas ou doenças causadas pela ação danosa de seres considerados nocivos. Em nível nacional, os órgãos competentes responsáveis pela execução e fiscalização do uso destes compostos são Instituto Brasileiro do Meio Ambiente (IBAMA), Agência Nacional de Vigilância Sanitária (ANVISA), Ministério do Meio Ambiente (MMA), Ministério da Saúde e o Ministério da Agricultura e Pecuária (COSTA; ROHLFS, 2011). 
Numa das tentativas de se monitorar os teores de contaminantes nos alimentos, a ANVISA o faz através do PARA - Programa de Análise de Resíduos de Agrotóxicos em Alimentos. É com base nos dados obtidos por este programa que os produtores e autoridades competentes norteiam práticas de manejo e políticas públicas de prevenção e repressão ao uso inadequado destes compostos. Mas segundo informações do PARA, a constatação da presença de teores de produtos químicos proibidos em alguns alimentos consumidos pela população mostra que há brechas nas políticas de controle no país (COSTA e ROHLFS, 2011). Esse dado serve de alerta para avaliar se as medidas de monitoramento que estão sendo realizadas pelos órgãos competentes estão de fato sendo efetivas e sugere que se faça um reconhecimento de quais medidas precisam ser revistas.

De acordo com Conway (2003), os agrotóxicos podem ser classificados quanto ao agente de ação (pesticidas, nematicidas, inseticidas, herbicidas, fungicidas, rodenticidas, acaricidas, molusquicidas, algicidas, etc.), grupo químico (organoclorados - OCs, cloro-fosforados, piretroides - PIRs, organofosforados - Ofs, carbamatos - CARs, Triazinas - TRIs), como cita Bastos et al., (2011), finalidade ( agricultura - agente fitossanitário, veterinária, uso doméstico - agrotóxico domissanitário), grau de toxicidade (I - extremamente tóxico, II - Altamente tóxico, III medianamente tóxico, IV - pouco tóxico). Sob orientação legal, com base em dados estabelecidos pela portaria no3/MS/SNVS de 16 de janeiro de 1992, da Agência Nacional de Vigilância Sanitária, os pesticidas devem apresentar também em seus rótulos, faixas coloridas classificando-os em: I - extremamente tóxico - cor vermelha, II - Altamente tóxico - cor amarela, III - medianamente tóxico - cor azul, IV - pouco tóxico - cor verde.

Dentre os inseticidas e alguns herbicidas, a classe dos organofosforados se destaca, os carbamatos aparecem no controle de fungos e ervas daninha. As triazinas como os herbicidas e os piretroides no combate a insetos (MCKINLAY et al., 2008).

\subsection{IMPACTOS}

\subsubsection{Ambientais}

O Brasil é um país com dimensões continentais e por ter um perfil extremamente agrícola, os produtores encontraram nos pesticidas um meio de incrementar sua produção e terem seus produtos melhorados qualitativamente. Aliado a isso, podemos acrescentar os baixos custos, a redução do trabalho e gastos de energia. Pelos números significativos que aparecem na produção agrícola nacional, observamos que este objetivo foi atingido. Contudo, o preço cobrado para o trabalhador rural - que lida diretamente com o tóxico, para o consumidor - que recebe cargas cada vez maiores de resíduos, e para o meio ambiente, tem sido alto demais com base nos resultados de pesquisas na área (COUTINHO et al., 2005).

Os pesticidas representam grande ameaça para o homem quando manuseados de forma inadequada, e no meio ambiente é um potencial poluidor quando descartados indevidamente. Os agrotóxicos são sintetizados com o objetivo de ser tóxico a grupos determinados, mas o comportamento destes químicos é muito complexo e na maioria das vezes não segue a rota programada podendo provocar danos em outras espécies. Muitos estudos têm sido realizados no sentido de minimizar o uso destes compostos, bem como, dar o devido tratamento aos corpos receptivos destes produtos. 
Com base na portaria Federal no 329/85, do Ministério da Agricultura, o Brasil começou a restringir ou mesmo banir o uso de alguns compostos, como é o caso dos organoclorados, tendo seu uso restrito para fins específicos. Mas, infelizmente, o Brasil continua na rota de muitos outros produtos já banidos em outros países como, por exemplo, o Paration, Carbofuran e o Paraquat que tem seus usos proibidos na China em 2006, União Europeia em 2005 e 2006, respectivamente (COSTA; ROHLFS, 2011). Pesquisas apontaram a correlação entre doenças crônicas e o uso inadequado de pesticidas.

\subsubsection{Na Saúde Pública}

As principais rotas de contaminação por agrotóxicos em humanos segundo Moreira et al., (2002) segue a via ocupacional, ambiental e a alimentar. A via ocupacional perfaz $80 \%$ dos casos de registro de contaminação. Ela está relacionada com o contato direto com estes compostos, como é o caso dos trabalhadores rurais. O comportamento do agrotóxico no ambiente é bem complexo, pois muitas variáveis interferem em sua atuação. Os organofosforados e organoclorados se destacam pela sua persistência no meio ambiente e efeito carcinogênico. Mesmo sendo utilizado para um fim específico, ele possui um grande potencial de modificar o perfil solo e atingir a fauna e flora, lençóis freáticos ou corpos hídricos, e até mesmo ser levado pelos ventos e atingir outras áreas. A via alimentar se caracteriza pela ingestão de alimentos contaminados. De acordo com o tempo (curto, médio ou longo) de exposição a estes químicos o grau de intoxicação pode ser classificado como agudo, subagudo e crônico, sendo que os seus efeitos deletérios variam de pessoa a pessoa (Fundação Nacional de Saúde, 2010; BRASIL, 2010).

Dentre os malefícios já relatados na literatura encontramos efeitos neurológicos diversos, má formação congênita, efeitos teratogênicos e carcinogênicos, problemas de esterilidade e psicomotores, aborto, deficiência cognitiva, cefaléia, fraqueza, tonturas, tremores, endocrinopatias, dentre outras (COSTA; ROHOLFS, 2011; LACASANÃ et al., 2010; OSSONDRO et al., 2009; CAROZZA et al., 2009; GENIUS, 2008; COLOSIO et al., 2009). A Agency for Toxic Substances and Disease Registry é um banco de registro internacional de risco toxicológico por produtos químicos que pode ser acessado (Agency for Toxic Substances and Disease Registry, 2010). Já no Brasil, um sistema ligado a Fiocruz, o SINITOX - Sistema Nacional de Informações Tóxico-Farmacológicas - disponibiliza informações relativas a números de casos registrados por intoxicação por agrotóxicos anualmente. No entanto, possivelmente, estes números devam ser bem mais expressivos, pois nem todos os casos ocorridos são notificados no sistema (Sistema Nacional de Informações Tóxico-Farmacológicas, 2010).

Muitas destas intoxicações podem ocorrer não somente pelo contato direto com o pesticida como também pela ingestão de alimentos contaminados. Por conta disto, muitos pesquisadores têm debruçado sua atenção sobre a permanência de resíduos destes compostos em diversas culturas consumidas pela população. Portanto, o produtor deve ter todo um cuidado na dosagem da aplicação do produto para que ele não exceda os limites toleráveis e não por menos, conhecer as características básicas do químico que está aplicando em sua cultura. Mas a prática mostra que isso não ocorre na maioria dos casos (Moreira, 2002).

O Instituto Nacional de Metrologia, Qualidade e Tecnologia, através de estudos realizados mediante avaliação das propriedades farmacológicas, toxicológicas, metabólicas e físico-químicas dos produtos utilizados na composição de agrotóxicos, estabelece a IDA (ingestão diária aceitável 
em $\mathrm{mg} / \mathrm{kg}$ ) para cada ingrediente ativo. O limite máximo de resíduo - LMR - permitido no alimento sem que se cause dano à saúde pública é estabelecido com base nos dados da IDA. Uma das maiores complicações no controle por parte do consumidor é que não há uma maneira visível de se reconhecer um alimento que apresenta percentuais de toxicidade acima do permitido. Neste contexto, os alimentos conhecidos como "orgânicos" têm ganhado espaço, mas ainda é um mercado inexpressivo (ROSSI, 2012).

\section{PROCESSOS DE DESCONTAMINAÇÃO DE POLUENTES}

\subsection{Processos Físico-Químicos}

O advento da Revolução Industrial trouxe consigo uma série de mudanças e uma delas foi o aumento na geração de resíduos. Esse excedente foi descartado no meio ambiente por muitos anos sem que houvesse nenhum tipo de preocupação no seu descarte. Nos últimos anos, observou-se um crescente desenvolvimento de estudos procurando mitigar os impactos causados por esses resíduos. Algumas das medidas adotadas são a conscientização sobre os riscos embutidos em tal prática sobre a saúde humana e recursos naturais, a adoção de novas normas e legislações que normatizem o uso, o processamento e descarte dos pesticidas, a adaptação e otimização de processos de produção industrial, a utilização de modelos de tratamento já conhecidos (adsorção em carvão ativado, air-stripping, oxidação biológica, incineração) como também a busca de novas tecnologias (por exemplo, os processos oxidativos avançados) visando assim a diminuição do impacto ambiental gerado pela descarga destes materiais (MORAIS, 2005).

Os processos oxidativos avançados (POA) aparecem neste cenário como uma proposta viável, principalmente, onde os sistemas de tratamento convencionais não são eficientes para remoção de poluentes persistentes e efluentes de elevada carga orgânica (AMORIM et al., 2009). Em linhas gerais, esses processos visam oxidar compostos orgânicos complexos a moléculas mais simples $\left(\mathrm{H}_{2} \mathrm{O}, \mathrm{CO}_{2}\right)$, ou mesmo a sua mineralização. Essa reação se baseia na geração e usos de radicais hidroxil altamente oxidantes e não seletivos (TARR, 2003; OLIVER et al., 2000) e existem muitos métodos para se gerar estes radicais (MUNTER, 2001). Dentre estes podem ser citados os que se utilizam da absorção de luz UV (fotoquímicos) e os onde não há a absorção de luz UV (não fotoquímico). Outros processos oxidativos envolvem a participação do permanganato $\left(\mathrm{MnO}_{4}{ }^{-}\right)$, perssulfato $\left(\mathrm{S}_{2} \mathrm{O}_{8}{ }^{-2}\right)$. Os sistemas podem ainda ser classificados em homogêneos ou heterogêneos. Estes se subdividem em homogêneo com irradiação $\left(\mathrm{O}_{3} / \mathrm{H}_{2} \mathrm{O}_{2} / \mathrm{UV} ; \mathrm{O}_{3} / \mathrm{UV}\right.$; $\left.\mathrm{H}_{2} \mathrm{O}_{2} / \mathrm{UV} ; \mathrm{Fell} / \mathrm{H}_{2} \mathrm{O}_{2} / \mathrm{UV}\right)$ sem irradiação $\left(\mathrm{O}_{3} / \mathrm{H}_{2} \mathrm{O}_{2} ; \mathrm{Fell} / \mathrm{H}_{2} \mathrm{O}_{2}\right)$, heterogêneo com irradiação (semicondutor/UV; semicondutor $/ \mathrm{H}_{2} \mathrm{O}_{2} / \mathrm{UV}$ ). O Reagente Fenton é caracterizado pela combinação de peróxido de hidrogênio com íons ferrosos como exposto anteriormente (AZBAR et al., 2004)

Os POA se caracterizam pela sua capacidade de mineralização dos contaminantes, pelo forte poder oxidante, cinética rápida e a não especificidade de ação. São utilizados em geral no tratamento de efluentes e águas residuais, na remediação de solos e águas subterrâneas, desinfecção e remoção de odores. Segundo Hsueh et al., (2005) nos efluentes de indústria têxtil, essas águas residuais são descoloridas pela ação dos radicais hidroxila sobre as ligações azo insaturadas do cromóforo. De acordo com Andreozzi et al., (2002), Chou et al., (2001), Centi et al., (2000) e Dantas et al., (2006), os óxidos de ferro têm sido utilizados como catalisadores no processo Fenton inclusive para a remoção de corantes. O controle de odores, por exemplo, pode ser conduzido pela degradação (através do tratamento bioquímico da matriz geradora ou dos 
compostos exalados), como agente mascarante ou pelo uso de materiais adsorventes/absorventes para fixar os compostos responsáveis pelos odores. Dentre as técnicas utilizadas para amostras gasosas pode-se citar a fotocatálise, $\mathrm{O}_{3} / \mathrm{H}_{2} \mathrm{O}_{2} / \mathrm{UV}, \mathrm{O}_{3} / \mathrm{UV}, \mathrm{H}_{2} \mathrm{O}_{2} / \mathrm{UV}$. As principais vantagens na utilização destas técnicas citadas são: a cinética rápida, a não geração de passivos e a ausência de consumo de reagentes (fotocatálise). Contudo, algumas limitações são observadas ao se valer destes processos como a manutenção de reatores, as baixas vazões apresentadas e o consumo de energia elétrica. Para as amostras líquidas temos como melhores opções as técnicas de fenton, fenton modificado, $\mathrm{O}_{3}$ e $\mathrm{H}_{2} \mathrm{O}_{2}$.

O maior número de aplicações destes processos é direcionado principalmente para a degradação de contaminantes como surfactantes, pesticidas, fármacos, amônia, dentre outros em matrizes como efluentes industriais de diversas naturezas, esgoto, água de abastecimento e subterrânea, etc. Mesmos sendo observadas relevantes vantagens sobre as técnicas convencionais, os POA encontram alguns obstáculos para a aplicação em larga escala (GALINDO et al., 2001).

$\mathrm{Na}$ tabela 1 estão relacionados Processos Oxidativos Avançados e suas principais vantagens e desvantagens.

Tabela 1: Processos Oxidativos Avançados

\begin{tabular}{l|ll|l}
\hline \multicolumn{1}{c|}{ PROCESSO } & \multicolumn{1}{c|}{ VANTAGEM } & \multicolumn{1}{c}{ DESVANTAGEM } \\
\hline $\begin{array}{l}\text { Fenton/Fenton } \\
\text { Modificado }\end{array}$ & $\bullet \begin{array}{l}\text { Baixa exposição humana } \\
\text { Ozonização }\end{array}$ & $\bullet \quad \begin{array}{l}\text { Geradores de ozônio comerciais } \\
\text { - Cinética rápida }\end{array}$ & $\begin{array}{l}\text { Adição de catalizador ou alteração de } \\
\mathrm{pH}\end{array}$ \\
\hline Fotoativados & $\bullet \begin{array}{l}\text { Geralmente apresentam uma } \\
\text { eficiência maior que os não } \\
\text { fotoativados }\end{array}$ & $\begin{array}{l}\text { Corrosão das instalações } \\
\text { pH }\end{array}$ & $\begin{array}{l}\text { Consumo de catalisador ou alteração de } \\
\text { turbidez }\end{array}$ \\
\hline Fotocatálise & $\bullet \quad \begin{array}{l}\text { sem consumo de reagentes } \\
\text { baixa exposição humana }\end{array}$ & $\begin{array}{l}\text { manutenção dos reatores } \\
\text { consumo de energia elétrica } \\
\text { turbidez }\end{array}$ \\
\hline
\end{tabular}

Fonte: LOCATELLI (2011)

\subsection{Processos Biológicos}

É cada dia mais crescente o interesse por tecnologias que possam minimizar os impactos causados pelo descarte de inadequado de poluentes no meio ambiente. A utilização de processos biotecnológicos tem-se mostrado viável. Processos de biorremediação - que podem se utilizar de plantas, bactérias, fungos ou produtos biológicos - com fins de tratamento de áreas contaminadas já vêm sendo realizados há décadas e continua sendo um campo promissor de pesquisas devido aos bons resultados obtidos (RODRIGUES, 2006).

\subsubsection{Características Gerais dos Fungos}

São seres eucarióticos (com um só núcleo como as leveduras, ou multinucleados, como se observa entre os fungos filamentosos ou bolores) heterotróficos (saprofíticos ou parasitários), simbiontes. Na sua maioria, são organismos aeróbios que produzem longos filamentos chamados de hifas (tubos sinuosos curvados) cujo conjunto forma uma massa - o micélio. Outros podem formar também um pseudomicélio que pode agrupar-se ou justapor-se, porém nunca formando 
tecidos verdadeiros. Todos os fungos têm parede celular e esta é formada essencialmente de celulose e quitina, um polissacarídeo encontrado também no exoesqueleto de artrópodes, por exemplo. (ESPOSITO; AZEVEDO, 2010; GRIFFIN, 1994). Essa parede é de consistência porosa, aparentemente devido à existência de diminutos poros ou canais (BURNETT, 1976).

Os fungos juntamente com as bactérias heterotróficas são os agentes mais importantes de degradação na Terra (ESPOSITO; AZEVEDO, 2010), tendo uma atuação tão importante para a vida no planeta quanto os produtores (RAVEN, 2007). Em especial, os fungos são considerados biodegradadores eficientes de polímeros de plantas naturais como lignina e celulose. Contudo, também degradam outros tipos de moléculas orgânicas como: ceras, borrachas, fenol, benzeno, tolueno, xileno e xenobióticos presentes em ecossistemas florestais onde eles são os principais decompositores de substância orgânica que impregna as células, as fibras e os vasos do vegetal, tornando-os isolados do meio. Constituem-se no grupo mais expressivo numericamente, excetuando-se os insetos, distribuídos nos mais diversos habitats. Pode ser encontrados compondo a biota do solo, livres ou associados a vegetais ou outros grupos, atuando principalmente na reciclagem de nutrientes (MODA et al., 2005).

Esses eucariotos são economicamente importantes destacando-se em diversas áreas como médica - na produção de ácidos orgânicos para produção de fármacos (antibióticos), ciclosporina, fitopatológica - como pragas de culturas de alto valor comercial, ecológica - como simbiontes (liquens e micorrizas), como controle biológico e em processos de biorremediação, industrial - pela produção enzimática (celulases, lacases, xilanases, pectinases, amilases) dentre outros (ESPOSITO; AZEVEDO, 2010; RAVEN, 2007; RODRIGUES; MARINHO, 2012).

Popularmente os fungos são conhecidos como bolores, frieiras, cogumelos que podem ser comestíveis ou tóxicos por conterem substâncias alucinógenas. Mas a importância deste grupo muito excede essa leiga visão. O universo destes organismos é mais amplo e a cada dia mais pesquisas são desenvolvidas tendo os fungos como protagonistas e os promissores resultados têm incentivado novas pesquisas.

Conhecer a sua fisiologia é um ponto chave para o sucesso de trabalhos em reatores ou na biorremediação de poluentes utilizando agentes fúngicos, tendo em vista que a otimização de sua atuação é influenciada por alguns fatores como pH, temperatura, composição do meio, oxigênio, gás carbônico e tamanho do inóculo (RODRIGUES; MARINHO, 2012).

\subsubsection{Fisiologia dos Fungos}

Rodrigues e Marinho (2012) definiram fisiologia como sendo o estudo dos processos fisico-químicos necessários para o funcionamento de um organismo (anabolismo e catabolismo). Segundo Esposito e Azevedo (2010) os fungos nunca são fotossintéticos, mas podem metabolizar uma grande variedade de fontes de carbono, incluindo açúcares e óleos.

De acordo com Carlile e Watkinson (1996), os fungos podem obter energia por processos aeróbios, anaeróbios ou fermentativos. A forma utilizada vai depender da espécie fúngica em questão, que em sua maioria se utiliza do primeiro processo citado.

Eles ocupam diferentes nichos ecológicos podendo atuar como saprófitos (vivendo sobre matéria orgânica morta), parasitas (quando se alimentam de matéria viva) ou mesmo simbiontes (em associação com vegetais superiores, algas e cianobactérias). Nos dois primeiros casos, as substâncias são ingeridas por absorção depois de serem parcialmente digeridas no exterior das 
paredes celulares por enzimas produzidas pelos próprios fungos de maneira que possam ser absorvidas. O principal polissacarídeo armazenado pelos fungos é o glicogênio que é também armazenado pelos animais (ALEXOPOULOS et al., 1996).

Os nutrientes absorvidos compõem a solução que rodeia a célula e devem possuir um tamanho adequado para que possam atravessar as camadas celulares: parede, membrana celular ou protoplasma antes de alcançar o citoplasma onde serão metabolizados (ESPOSITO; AZEVEDO, 2010). Retiram os nutrientes do meio ambiente circundante, através da digestão enzimática externa, que transforma as substâncias de forma que possam ser absorvidas, tendo normalmente preferência pela glicose como fonte de carbono. Eles necessitam de quatro elementos básicos: $\mathrm{H}, \mathrm{O}, \mathrm{C}$ e $\mathrm{N}$, além de outros elementos em menor quantidade: $\mathrm{P}, \mathrm{S}, \mathrm{Mg}, \mathrm{Fe}$, $\mathrm{Zn}, \mathrm{Cu}, \mathrm{Mb}$, sendo que alguns carecem ainda de determinados fatores de crescimento, como por exemplo a tiamina. De maneira geral, para o seu crescimento, necessitam de uma fonte orgânica de $\mathrm{C}$ ou de uma fonte inorgânica de N. A incorporação de macronutrientes em pesquisas laboratoriais é sugerida como necessária para o bom crescimento dos fungos segundo a maioria das literaturas consultadas (ESPOSITO; AZEVEDO, 2010; ALEXOPOULOS et al., 1996; CARLILE; WATKINSON, 1996).

No tocante aspecto reprodutivo, os fungos diferem das plantas e animais pela não obrigatoriedade do ciclo de vida. Em meios não favoráveis os fungos desenvolver formas de resistência - os esporos. Estes podem ser equivalentes ao papel das sementes nos vegetais, como podem também estar associados à sobrevivência - ascomicetos levuriformes - ou, como no caso dos basidiomicetos unicelulares estão relacionados à dispersão e não necessariamente ao aumento populacional de organismos fúngicos (CARLILE; WATKINSON, 1996). Em suma, os esporos estão relacionados à reprodução, sobrevivência e dispersão apresentando uma ampla variedade de formas. $O$ tipo de divisão celular que precederá a formação deste esporo é que irá definir a sua natureza assexuada (mitose) ou sexuada (meiose). Observa-se que esse o processo de esporulação pode ser desencadeado por alguns fatores como a escassez de nutriente, temperatura, umidade e luz.

Entendendo crescimento como definiu Prosser (1995) como um aumento de biomassa a partir de um incremento ordenado das estruturas celulares, as taxas de crescimento entre os fungos vai depender da morfologia que ele apresenta como também de fatores ambientais que exercem grande influência sobre o desenvolvimento dos mesmos. De modo que diferentes espécies apresentam diferentes ótimos e crescem em distintas faixas para cada fator. Embora alguns grupos se desenvolvam em condições extremas, a maioria se enquadra numa faixa que em relação ao $\mathrm{pH}$, este varia entre 5 e 7, com umidade alta. E em relação à temperatura apresentam ótimos de $15^{\circ} \mathrm{C}$ e $40^{\circ} \mathrm{C}$ (ESPOSITO; AZEVEDO, 2010).

Wallstron (2002) pontuou que para os fungos filamentosos que possuem uma taxa de crescimento relativamente mais baixa que a de bactérias, por exemplo, essa característica poderá ser suplantada pela rápida proliferação hifal (alongamento celular da extremidade da hifa e ramificação) e, consequentemente, uma atuação enzimática mais efetiva sobre o meio que será colonizado. Mas deve-se ser ressaltado como mesmo apresentou Robinson (1978) que a taxa de crescimento das hifas variam entre diferentes espécies, tomando assim como exemplo a Neurospora crassa que tem uma velocidade de crescimento em torno de 1.5 a $6 \mathrm{~mm} . \mathrm{h}^{-1}$, ao passo que nas cepas do gênero Pennicillium observa-se valores bem inferiores de $0.01 \mathrm{a} 0.02 \mathrm{~mm} \cdot \mathrm{h}^{-1}$. 
O micélio em formação poderá apresentar diferentes conformações sejam elas longas e difusas, ou curtas e cheias de ramificações e até mesmo uma mescla de ambas as formas. A genética e a interação com o meio é que determinará esse comportamento. A formação de pellets também poderá ser observada em virtude deste rápido crescimento. Na estrutura destes podem se notar a presença de três camadas arranjadas esfericamente compostas pelo núcleo ou core, camada intermediária e periferia. Já nos fungos levuriformes, o crescimento se caracteriza pelo aumento de forma proporcional no tamanho da célula (aumento de biomassa) e sequencial divisão celular (aumento populacional). Brotamento é um exemplo típico deste tipo de duplicação que ocorre em leveduras.

Estudos realizados com fungos têm-se mostrado eficazes na remoção de uma gama variada de substratos.

\subsection{Degradação de poluentes por Fungos}

Desde a era da industrialização observa-se o crescimento desordenado de centros urbanos e industriais. Acrescida a essa realidade, pode-se mencionar também a retirada de recursos da natureza e descarte de resíduos (compostos fenólicos, corantes, fertilizantes químicos e pesticidas, por exemplo), que sem o devido gerenciamento tem causado um impacto negativo devido a carga extremamente poluidora de muitos de seus rejeitos. Essa postura tão corriqueira tem inquietado sobremaneira a comunidade científica que a cada dia busca soluções para contornar, ou, pelo menos, mitigar esses impactos. A utilização de processos biotecnológicos como consórcios de microorganismo e/ou enzimas e surfactantes tem se mostrado uma perspectiva viável (RODRIGUES, 2006).

Os fungos são os agentes mais importantes de degradação na Terra. Além disso, são considerados biodegradadores eficientes de polímeros de plantas naturais como lignina e celulose, mas também degradam outros tipos de moléculas orgânicas como: ceras, borrachas, fenol, benzeno, tolueno, xileno e xenobióticos, presentes em ecossistemas florestais onde eles são os principais decompositores de substância orgânica que impregna as células, as fibras e os vasos do vegetal, impedindo assim a entrada e deslocamento de agentes externos (PRENEFETA BOLDÚ, 2002).

O emprego de fungos no tratamento de efluentes começou a ser estudado nos últimos trinta anos do século XX, tendo ocorrido, nas duas últimas décadas, um incremento nas pesquisas de biodegradação por fungos (WANDERLEY, 2007). O emprego de reatores com fungos têm sido usados nestas investigações com satisfatórias respostas pelo fato deles se mostrarem versáteis na degradação eficiente de moléculas como: fenol, benzeno, tolueno, xileno e xenobióticos (PRENAFETA-BOLDÚ, 2002; PASSOS, 2006). Segundo Dias (2000), o grande desafio nas pesquisas com estes microrganismos é conhecer a capacidade degradativa de matéria orgânica ou sintética por esses grupos e aperfeiçoar esses processos.

\subsubsection{Capacidade de Degradação por Aspergillus niger}

Jernejc e Legisa (2004) destacaram o papel do Aspergillus niger pelo seu potencial biotecnológico na produção enzimática e de ácidos orgânicos. 
Pinheiro et al., (2007) estudaram a capacidade de degradação de fenol de um efluente sintético em reatores em batelada, sem aeração artificial, sem agitação, inoculados com fungos da linhagem Aspergillus niger AN400 e utilizando o açúcar refinado como fonte primária de carbono. Para o estudo foram utilizadas quatro diferentes concentrações de fenol $(1000 \mathrm{mg} / \mathrm{L}$, $500 \mathrm{mg} / \mathrm{L}, 250 \mathrm{mg} / \mathrm{L}$ e $100 \mathrm{mg} / \mathrm{L}$ ), e os reatores divididos em três lotes: C, contendo apenas efluente sintético; FF, contendo efluente sintético e fungo; FFA, contendo efluente sintético, fungo e açúcar refinado. Os reatores foram conduzidos por um período de cinco dias. Os resultados do experimento mostraram que houve eficiência na remoção de fenol de, aproximadamente $100 \%$, a partir do terceiro dia de tratamento.

Os fungos se destacam no tratamento biológico de efluentes de refinarias de petróleo devido a sua capacidade enzimática de degradação de compostos policíclicos aromáticos de cadeia longa em compostos que podem ser assimilados pelo seu metabolismo. Os compostos fenólicos presentes nestas águas são potencialmente tóxicos para algumas espécies aquáticas e podem também alterar, mesmo em baixas concentrações, o gosto e odor no processo de tratamento com cloração em águas de abastecimento (ARANÃ et al., 2001). A grande plasticidade deste grupo os permite sobreviver e crescer em condições praticamente impossíveis para outros seres serem capazes de se utilizar de compostos recalcitrantes utilizando-os como fonte energética (EGGEN; MAJCHERCZYK, 1998; ESPOSITO; AZEVEDO, 2004; SANTOS; LINARDI, 2004). Nestas condições, Griffin (1994), Assadi e Jahangiri (2000) sugeriram que para uma intensificação da atividade fúngica, seja adicionada a glicose como substrato primário. No entanto, Santella et al., (2009), ressaltaram que ela somente seja adicionada para a partida dos reatores, facilitando o crescimento fúngico inicial. Godjevargova et al., (2003) acrescentaram que para otimizar ainda mais a eficiência na remoção seja o uso de células imobilizadas no decurso do processo.

Nas águas residuárias de refinarias de petróleo pode-se encontrar taxas variadas de compostos nitrogenados (amônia, nitrito e nitrato). Embora a presença de elevadas concentrações de amônia cause preocupação para a operação de sistemas de tratamento, a presença dela é vital para o desenvolvimento dos fungos, já que eles podem utilizá-la diretamente ou a partir da redução de nitratos (SANTAELLA et al., 2009). Utilizando assim tanto fontes orgânicas como inorgânicas de nitrogênio (GRIFFIN, 1994). Takaya (2002) pontuou sobre a flexibilidade que os fungos têm de adaptar-se a diferentes concentrações de oxigênio utilizandose de diferentes rotas metabólicas (desnitrificação, amonificação e respiração aeróbia). Essa característica garante a este grupo inúmeras vantagens em relação às bactérias quanto da sua utilização em tratamento de efluentes.

Os fungos filamentosos foram apresentados por Eggen e Majcherczyk (1998) como mais efetivos na produção de enzimas extracelulares oxidativas (ligninases, proteases, celulases, dentre outras). O A. niger, trabalhando numa faixa ótima de pH entre 3,0 e 4,0 (GRIFFIN, 1994), se destacou dentre os fungos filamentosos pela comprovada capacidade de degradação de compostos recalcitrantes de diversas indústrias (cervejarias, castanha de caju, farmacêutica, refinarias de petróleo, degradação de paration em água (GARCIA et al., 2000; HERNÁNDEZ et al., 2006; MIRANDA et al., 1996; SANTOS et al., 2006; VASSILEV et al., 1997).

A espécie $A$. niger possui um grande desempenho na remoção de DQO, como também na degradação de compostos recalcitrantes como a atrazina, metil paration como também outros pesticidas organofosforados (GARCÍA, 2003; MIRANDA et al., 1996; VASSILEV et al., 1997; GARCÍA et al., 2000) Estudando quatro reatores em batelada com o objetivo de avaliar o potencial de 
degradação da atrazina numa cultura mista de micro-organismos anaeróbios, Glosh e Philip (2004), observaram que o melhor resultado ocorreu no reator onde a atrazina foi empregada como única fonte de carbono e nitrogênio, tendo como percentuais de mineralização de 43 à $45 \%$ do pesticida com um TDH de 5 dias.

\section{CONCLUSÃO}

Os pesticidas são compostos largamente utilizados na agricultura e pecuária com o objetivo de combater pragas e ervas daninhas. Seu extenso uso principalmente nas últimas décadas tem causado impacto não somente na saúde humana como também no meio ambiente. Embora existam no país órgãos de gestão para o uso de agrotóxicos, observa-se que o Brasil ainda se utiliza de produtos banidos em outros países, como também apresenta faixas de tolerância maiores que países da União Europeia, por exemplo. Várias são as patologias relacionadas à exposição a esses compostos. Os recursos naturais estão sendo comprometidos pelo intenso descarte destes produtos sem o devido tratamento. Na tentativa de recuperar essas áreas, várias pesquisas estão sendo desenvolvidas tendo como agentes de remediação, os microrganismos. A biorremediação é um processo que utiliza organismos vivos para mineralizar ou reduzir determinados compostos com potencial contaminante do meio ambiente. Os fungos têm se destacado como agentes biorremediadores pela capacidade de degradação de um amplo espectro de compostos, muitos deles refratários para a maioria dos microrganismos.

\section{REFERÊNCIAS BIBLIOGRÁFICAS}

1. ALEXOPOULOS, C.J., MINS, C.W.; BLACWEL, M. Introductory Mycology. 4. P. 26-60. J. Wlew \& Sons, New York, 1996.

2. ALVES FILHO, J.P. Uso de agrotóxicos no Brasil controle social e interesses corporativos. São Paulo: Annablume. 2002. 188p.

3. AMORIM, C. C.; LEÃO, M. M. D.; MOREIRA, R. F. P. M. Comparação entre diferentes processos oxidativos avançados para a degradação de corante azo. Eng Sanit Ambient . v. 14, n. 4, p. 543-550, out/dez. 2009.

4. Associação Niteroiense de Deficientes Físicos. Tecnologia em primeiro lugar. Defesa Vegetal, p. 16-17, 2009.

5. ANDREOZZI, R.; D'APUZZO, A.; MAROTTA, R. Oxidation of aromatic substrates in water/goethite slurry by means of hydrogen peroxide. Water Research, v. 36, n. 19, p. 46914698, 2002.

6. Agência Nacional de Vigilância Sanitária. Programa de análise de resíduos de agrotóxicos em alimentos. Relatório Anual de 2009. Disponível em: <http://www.anvisa.gov.br/institucional/ anvisa/relatorios/relatorio2009/pdf/CDROM\%20miolo\%20relatorio\%20Anvisa2007.pdfhtt>. Acesso em: 24 de mai. 2013.

7. Agência Nacional de Vigilância Sanitária. Decreto 4074/02 regulamenta a Lei no 7.802 de 11 de julho de 1989 que dispõe sobre assuntos relativos aos agrotóxicos, seus componentes e afins, e dá outras providências. Disponível em:<http://portal.anvisa.gov.br/wps/content/ Anvisa+Portal/Anvisa/Inicio/Agrotoxicos+e+Toxicologia/Assuntos+de+Interesse/Legislacao/L 
egislacao+de+Agrotoxicos+Componentes+e+Afins/Decretos>. Acesso em: 25 de mai. 2013.

8. ARAÑA, J. et al. Highly concentrated phenolic wastewater treatment by the Photo-Fenton reaction, mechanism study by FTIR-ATR. Chemosphere. V. 44, p.1017-1023. 2001.

9. ASSADI, M.M.; JAHANGIRI, M. R. Textile wastewater treatment by Aspergillus niger. Desalination.V. 141, p. 1-6. 2001.

10. Agency for Toxic Substances And Disease Registry. Minimal Risk Levels. Disponível em: <http://www.atsdr.cdc.gov/mrls/mrllist.asp>. Acesso em: 24 mai. 2013.

11. AZBAR, N.; YONAR, T.; KESTIOGLU, K. Comparison of various advanced oxidation processes and chemical treatment methods for COD and color removal from polyester and acetate fiber dyeing effluent. Chemosphere, v. 55, n. 1, p. 35-43, 2004.

12. BASTOS, L. H. P.; CARDOSO, M. H. W. M.; NÓBREGA, A. W.; JACOB, S. C. Possíveis fontes de contaminação do alimento leite, por agrotóxicos, e estudos de monitoramento de seus resíduos: uma revisão nacional. Cad. Saúde Coletiva, Rio de Janeiro, 19 (1): 51-60, 2011.

13. BRASIL, 2010. Ministério da Saúde, Protocolo de Atenção à Saúde dos Trabalhadores Expostos a Agrotóxicos. 2006. Disponível em: <http://portal.saude.gov.br/portal/ arquivos/pdf/integra_agrotoxicos.pdf>. Acesso em: 24 mai. 2013.

14. BRASIL. Ministério da Saúde. Secretaria de Ciência Tecnologia e Insumos Estratégicos. Exposição humana a resíduos organoclorados na cidade dos meninos. Município de Duque de Caxias, Rio de Janeiro. 2. ed. Brasília, 2003. 58 p.

15. BRASIL. LEI № 7.802, de 11 de julho de 1989. Dispõe sobre assuntos relativos a agrotóxicos e seus componentes afins, e dá outras providências. Disponível em:<http://www.planalto. gov.br/ccivil_03/leis/17802.htm>. Acesso em: 24 de mai. 2013.

16. BRASIL. Ministério da agricultura, pecuária e abastecimento. Decreto no 4074, de 04 de janeiro de 2002. Regulamenta a LEI no 7802, de 11 de julho de 1989. Dispõe sobre assuntos relativos a agrotóxicos e seus componentes afins, e dá outras providências. Disponível em: <http://www.planalto.gov.br/ccivil_03/decret/2002/d4074.htm>. Acesso em: 15 mai. 2013.

17. BURNETT, J.H. Fundamentals of mycology. 2. ed. Edward Arnold, London. 1976. 674p.

18. CARLILE, M. J.; WATKINSON, S. C. The Fungi. San Diego: Academic Press - Harcourt Brace \& Company, 1996.

19. CAROZZA, E. S.; Wang, Q.; Horel, S.; Cooper, S. Agricultural pesticides and risk of childhood cancers. International Journal of Hygiene and Environmental Health, v. 212, p. 186-195, 2009.

20. CENTI, G. et al. Catalytic wet oxidation with $\mathrm{H}_{2} \mathrm{O}_{2}$ of carboxylic acids on homogeneous and heterogeneous Fenton-type catalysts. Catalysis Today, v. 55, n. 1-2, p. 61-69. 2000.

21. CHOU, S.; HUANG, C.; HUANG, Y.H. Heterogeneous and homogeneous catalytic oxidation by supported $\gamma$-FeOOH in a fluidized-bed reactor: kinetic approach. Environmental Science \& Technology, v. 35, n. 6, p. 1247-1251. 2001.

22. COLOSIO, C.; Tirmani, M.; Brambilla, G.; Colombi, A.; Moretto, A. Neurobehavioural effects of pesticides with special focus on organophosphorus compounds: which is the real size of the 
problem? NeuroToxicology, v. 30, p. 1155-1161. 2009.

23. Conselho Nacional de Meio Ambiente. Disponível em:< http://www.mma.gov.br/port/ conama/legiabre.cfm?codlegi=23>. Acesso em: 25 de mai. 2013.

24. CONWAY, G. Produção de alimentos no século XXI biotecnologia e meio ambiente. São Paulo: Estação Liberdade. 2003. 375 p.

25. COSTA, F. L. F.; ROHLFS, D. B. Resíduos de agrotóxicos em alimentos: implicações para saúde pública e meio ambiente. Pontifícia Universidade Católica de Goiás Programa de PósGraduação em Biociências Forenses. 2011. Disponível em: $<$ http://www.cpgls.ucg.br/Arquivos

Upload/1/File/V\%20MOSTRA\%20DE\%20PRODUO\%20CIENTIFICA/SAUDE/52.pdf>. Acesso em: 20 mai. 2013.

26. COUTINHO et al. Pesticidas: mecanismos de ação, degradação e toxidez. Pesticidas: r. ecotoxicol. e meio ambiente. Curitiba, v. 15, p. 65-72, jan/dez. 2005.

27. DANTAS, T.L.P. et al. Treatment of textile wastewater by heterogeneous Fenton process using a new composite $\mathrm{Fe}_{2} \mathrm{O}_{3}$ /carbon. Chemical Engineering Journal, v. 118, n. 1-2, p. 77-82. 2006.

28. EGGEN, T.; MAJCHERCZYK, A. Removal of polycyclic aromatic hydrocarbons (PAH) in contaminated soil by white rot fungus Pleurotus ostreatus. International Biodeterioration and Biodegradation. v. 41, n. 2, p. 111-117. 1998.

29. EPA - United States Environmental Protection Agency. Disponível em: $<$ http://www.epa. gov/>. Acesso em: 24 de mai. 2013.

30. ERBACH, G. Pesticedes legislation in EU. Libraly briefing. Dispoinível em: $<$ http://www.euro parl.europa.eu/RegData/bibliotheque/briefing/2012/120291/LDM_BRI(2012)120291_REV1_ EN.pdf>. Acesso em: 20 de mai. 2013.

31. ESPOSITO, E.; AZEVEDO, J. L. de. Fungos: uma introdução à biologia, bioquímica e biotecnologia. 2a ed. Revisada. Caxias do Sul: Educs, 2010.

32. GALINDO, C.; JACQUES, P.; KALT, A. Photochemical and photocatalytic degradation of an indigolid dye: a case study of acid blue 74 (AB74). Journal of Photochemistry and Photobiology A: Chemistry. v. 141, p. 47-56. 2001.

33. GARCIA, I. G. et al. Removal of phenol compounds from olive Mill wastewater using Phanerochaete chrysosporium, Aspergillus niger, Aspergillus terreus and Geotrichum candidum. Process Biochemistry, v. 35, p. 751-758. 2000.

34. Biodegradation of phenol compounds in vinasse using Aspergillus terreus and Geotrichum candium . Wat. Res. V. 31, n 8 p. 2005-2011. 1997.

35. GENIUS, J. S. Toxic Causes of Mental Illness are Overlooked. NeuroToxicology, v. 29, p. 11471149. 2008.

36. GODJEVARGOVA, T. et al. Biodegradation of toxic organic components from industrial phenol production waste water by free and immobilized Trichosporon cutaneum R57. Process Biochemistry, v. 38, n. 6, p. 915-920. 2003. 
37. GHOSH, P. K.; PHILIP, L. Atrazine degradation in anaerobic environment by a mixed microbial consortium. Water Research, V. 38, pp. 2277-2284. 2004.

38. GRIFFIN, D. Fungal Physiology. New York: Wiley Liss. 1994.

39. HERNÁNDEZ, M.S. et al. Amylase production by Aspergillus niger in submerged cultivation on two wastes from food industries. Journal of Food Engineering, v. 73, n. 1, p. 93-100. 2006.

40. HSUEH, C.L. et al. Degradation of azo dyes using low iron concentration of Fenton and Fenton-like system. Chemosphere, v. 58, n. 10, p. 1409-1414. 2005.

41. Instituto Brasileiro de Geografia e Estatística. Censo Agropecuário. Disponível em: <http://www.ibge.gov.br>. Acesso em: 24 de mai. 2013.

42. JERNEJC, K.; LEGISA, M. A drop of intracellular $\mathrm{pH}$ stimulates citric acid accumulation by some strains of Aspergillus niger. Journal of Biotechnology, v. 112, n. 8, p. $289-297,2004$.

43. KLINGMAN, G.C.; ASHTON, F.M.; NOORDHOFF, L.J. Weed Science: principles and practices. 2. ed. New York: John Wiley. 449p. 1982.

44. KYRIACOU, A. et al. Combined bioremediation and advanced oxidation of green table olive processing watewater. Process Biochemistry. V. 40, p. 1404 - 1408, 2005.

45. LACASANÃ, M.; Lopes-Flores, I.; Rodriguez-Barranco, M.; Aguillar-Garduño, C.; MuñozBlanco, J.; Pérez-Méndez, O.; et al. Association between organophosphate pesticides exposure and thyroid hormones in floriculture workers. Toxicology and Applied Pharmacology, v. 243, p. 19-26. 2010.

46. LIMA, Paulo Junior Paz de. Possíveis doenças físicas e mentais relacionadas ao manuseio de agrotóxicos em atividades rurais, na região de Atibaia, SP/Brasil. 2008. 158 f. Dissertação (Mestrado) - Universidade de São Paulo, São Paulo, 2008.

47. LOCATELLI, M. A. F. Processos Oxidativos Avançados (POA) no tratamento in sito de corpos de águas superficiais. Disponível em: <http://www.ambiente.sp.gov.br/pomarurbano/files/ 2011/10/Dr-marco-antonio-fernandes-locatelli.pdf>. Acesso em: 24 de mai. 2013.

48. MARASCHIN, L. Avaliação do grau de contaminação por pesticidas na água dos principais rios formadores do pantanal mato-grossense. 2003. 90f , Dissertação ( Mestrado em Saúde e Ambiente) - Universidade Federal de Mato Grosso - UFMT, Cuiabá, 2003.

49. MCKINLAY, R.; Plant, J. A.; Bell, J. N.; Voulvoulis, N. Endocrine disrupting pesticides: Implications for risk assessment. Environment International, v. 34, p. 168-183. 2008.

50. MIRANDA, M.P. et al. Color elimination from molasses wastewater by Aspergillus niger. Bioresource Technology, v. 57, n. 3, p. 229-235. 1996.

51. MODA, E. M.; HORRI, J.; SPOTO, M. H. F. Edible mushrom Pleurotus sorjo-caju production on washed and supplemented sugarcane bagasse. Scientia Agricola, v. 62, n.10, p. 127-132. 2005.

52. MORACCI, L. F. S. Resíduos de agrotóxicos em lodo de estação de tratamento de água: validação de metodologia analítica utilizando cromatografia líquida acoplada à espectrometria de massas em Tandem (LC-MS/MS). 2008. Dissertação (Mestrado em Tecnologia Nuclear - Materiais). Instituto de Pesquisas Energéticas Nucleares. Universidade 
de São Paulo. São Paulo, 2008.

53. MORAIS, J.L. Estudo da potencialidade de processos oxidativos avançados, isolados e integrados com processos biológicos tradicionais, para tratamento de chorume de aterro sanitário. 2005. Tese (Doutorado em Química). Setor de Ciências Exatas. Universidade Federal do Paraná. Disponível em: <http://dspace.c3sl.ufpr.br/dspace/bitstream/handle/1884 /3523/TESE\%20DOUT\%20...?sequence=1 >. Acesso em: 24 de mai. 2013.

54. MOREIRA, J.C.; JACOB, S.C.; PERES, F.; LIMA, J.S. Avaliação integrada do impacto do uso de agrotóxicos sobre a saúde humana em uma comunidade agrícola em Nova Friburgo-RJ, Ciência e Saúde Coletiva. v,7, p. 1-22. 2002.

55. MUNTER, R. Advanced oxidation processes: current status and prospects. Proc. Estonian Acad. Sci., Chem . 50(2), 59-80. 2001.

56. NATIONAL RESEARCH COUNCIL. The future role of pesticides in US agriculture.Washington, D.C.: National Academy Press. 2000. Disponível em: <http://www.nap.sdu/books/ 0309065267/html/> Acesso em: 25 mai. 2013.

57. OLIVER, J.H.; HYUNOOK, K.; PEN-CHI, C. Decolorization of wastewater. Critical review. Environmental Science \& Technology, v. 30, n. 4, p. 499-505. 2000.

58. OSSONDO-LANDAU, M.; Rabia, N.; Jos-Pelage, J., Marquet, L. M.; Isidore, Y.; Saint-Aimé, C.; et al. Why pesticides could be a commom cause of prostate and breast cancers in the French Caribbean Island, Martinique. Ann overview on key mechanisms of pesticide-induced cancer. Biomedicine \& Pharmacotherapy. v. 63, p. 383-395. 2009.

59. PERES et al., Desafios ao estudo da contaminação humana e ambiental por agrotóxicos. Ciência \& Saúde Coletiva. v. 10, p. 27-37. 2005.

60. PINHEIRO, Z. B., DAMASCENO, E. P., SILVA, G. M. M., RODRIGUES, K. SAMPAIO, G. M. M. S. Degradação de fenol por Aspergillus niger AN400 em reatores em batelada. CONGRESSO DE PESQUISA E INOVAÇÃO DA REDE NORTE NORDESTE DE EDUCAÇÃO TECNOLÓGICA CONNEPI, 2007.

61. PRENAFETA BOLDÚ, F. X. Growth of on aromatic hydrocarbons: Environmental technology perspectives. Thesis Wageningen University, Wageningen, The Netherlands, 2002.

62. PROSSER, J. I. Kinetics of filamentous growth and branching. In: GOW, N. A. R.; GADD, G. M. (Eds). The Growing Fungus. Chapman \& Hall. UK, p. 301 - 318. 1995.

63. PUTZKE, J. e PUTZKE, M.T.L. Os Reinos dos Fungos. Santa Cruz do Sul: EDUNISC, 214 p. v.2, 2002.

64. RAVEN, P.H.; EVERT, R.F.; EICHHORN, S.E . Biologia Vegetal. 7 ed. Rio de Janeiro: Guanabara Koogan, 2007. 856 p.

65. RIBEIRO, M.L.; LOURENCETTI, C.; PEREIRA, S.Y.; MARCHI, M.R.R. Contaminação de águas subterrâneas por pesticidas: avaliação preliminar. Química Nova, São Paulo, SP, v. 30, n. 3, p. 688-694. 2007.

66. ROBINSON, P. M. Pratical fungal physiology. J. Wiley \& Ssons. p. 123. 1978. 
67. RODRIGUES, K. A. Uso de reatores biológicos com fungos para remoção de fenol de água residuária sintética. 2006. 145f. Tese (Doutorado em Saneamento) - Escola de Engenharia de São Carlos da Universidade de São Paulo, São Carlos, 2006.

68. RODRIGUES, K. A.; MARINHO, M. M. S. Fungos e Águas Residuárias Industriais: Nova Tecnologia. Recife: Imprima, 2012.

69. ROSSI, C.A. Resíduos de Agrotóxicos em Alimentos e riscos para a saúde humana. 10a Mostra acadêmica UNIMEP. 2012. Disponível em: < http://www.unimep.br/phpg/mostraacademica/ anais/10mostra/5/205.pdf>. Acesso em: 20 de mai. 2013.

70. SANTAELLA, S.T. et al. Tratamento de efluentes de refinaria de petróleo em reatores com Aspergillus niger. Engenharia Sanitária Ambiental, v. 14, n.1, p.139-148, jan/mar. 2009.

71. SANTOS, E.M.A. et al. Influência do tempo de detenção hidráulica em um sistema UASB seguido de um reator biológico com fungos para tratar efluentes de indústria de castanha de caju. Revista Engenharia Sanitária e Ambiental, v. 11, n. 1, p. 39-45, jan./mar. 2006.

72. SANTOS, V.L.; LINARDI, V.R. Biodegradation of phenol by a filamentous fungi isolated from industrial effluents - identification and degradation potencial. Process Biochemistry, v. 39, p. 1001-1006. 2004.

73. SINITOX. Sistema Nacional de Informações Tóxico-Farmacológicas. Fundação Oswaldo Cruz. Casos registrados de intoxicação humana. Disponível em: <http://www.fiocruz.br/sinitox _novo/media/tab06_brasil_2008.pdf>. Acesso em: 13 jul. 2010.

74. SUZUKI, D. The food we eat. An international comparison of pesticide regulations. David Suzuki Fundation. 2006. Dispinível em: < <http://www.davidsuzuki.org/publications/reports/ 2006/the-food-we-eat-an-international-comparison-of-pesticide-regulations/>. Acesso em: 20 de mai. 2013.

75. TAKAYA, N. Dissimilatory nitrate reduction metabolisms and their control in fungi. Journal of Bioscience and Bioengineering, v. 94, n. 6, p. 506-510. 2002.

76. TARR, M.A. Chemical degradation methods for wastes and pollutants, Nova lorque: Ed. Marcel Dekker, 2003.

77. THE EXTENSION TOXICOLOGY NETWORK. Pesticide information profiles. Disponível em: <http://extoxnet.orst.edu/pips/ghindex.html>. Acesso em: 10 nov. 2009.

78. TORRES, H. da G. A demografia do risco ambiental. In: TORRES, H.; COSTA, H. (Org.). População e meio ambiente: debates e desafios. São Paulo: Senac, 2000.

79. VASSILEV, N. et al. Olive mill waste water treatment by immobilized cells of Aspergillus niger and its enrichment with soluble phosphate. Process Biochemistry, v. 32, n. 7, p. 617-620. 1997.

80. WAISSMANN, W. Agrotóxicos e doenças não transmissíveis. Ciência \& Saúde Coletiva, v. 12, p. 15-24. 2007.

81. WALLSTRON, S.; DOWLING, K.; KARLSSON, S. Development and comparasion of test methods for evaluating formation of biofilms on silicones. Polymer Degradation, v.78, n.11, p. $257-$ 262. 2002. 
82. WANDERLEY, C. R. P. Aspergillus niger AN400 como inóculo de reatores em batelada para remoção de corante vermelho do congo em meio aquoso sintético. 2007. 70p. Dissertação (Mestrado em Engenharia Hidráulica e Ambiental, Universidade Federal do Ceará). Fortaleza, 2007.

83. WORLD HEALTH ORGANIZATION, WHO. Public health impact of pesticides used in agriculture. Genebra: World Health Organization, 1990. 